\section{SELECTED ISSUES ON THE METHODOLOGY OF DETERMINING THE EFFICIENCY OF A SHIP'S ENERGY SYSTEM IN DIFFERENT OPERATING STATES}

DOI 10.2478/ntpe-2018-0094

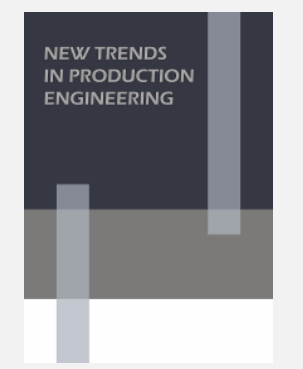

2018

Volume 1

Issue 1

pp. 747-754

\author{
PhD. Ryszard Michalski \\ PhD., DSc. Wojciech Zeńczak
}

West Pomeranian University of Technology, Poland

\begin{abstract}
The article presents the methodology and algorithm for determining the efficiency of a ship's energy system, which can be helpful at both operation and design stage. Knowledge of the methodology discussed here and the definitions of a ship's energy system's efficiency may be particularly useful for operators, as particularly complicated energy conversion chains exist on specialized units, such as fishing vessels, which have many devices that can be driven by different types of engines and transmissions. Proper disposal of energy streams allows for their optimal use and for a reduction in fuel consumption, whose cost constitutes the largest share of the vessel's operating costs.
\end{abstract}

Keywords: ship's energy system; efficiency; calculation methods

\title{
INTRODUCTION
}

Fuel costs currently constitute the largest share of total vessel operating costs; hence achieving high energy efficiency of a ship's energy system should be one of the priorities at the early design stage. Since ships practically sail under varied operating conditions and use more or less diverse technological devices related to the function they fulfill (e.g. fishing vessels, drilling vessels, cable vessels, etc.), having knowledge of the methodology for determining the efficiency of a ship's energy system should also be of concern to operators. Long-term operating conditions and more energy-intensive states should be taken into account when determining efficiency and not only nominal states which, in practice, occur sporadically.

The energy conversion chains in a ship's energy system may be more or less complex; particularly complex are those found on specialized units, in which many devices are operated that can be driven by hydraulic or electric motors or, in the simplest case, by a mechanical transmission from the main engine. It is then necessary to know a large amount of data pertaining to the efficiency of particular energy transformations in the chain to determine the efficiency of a complex energy system.

The article presents the methodology and algorithm for determining efficiency based on the example of a fishing vessel's energy system and depending on the dataset.

\section{ENERGY CONVERSION IN A SHIP'S ENERGY SYSTEM}

Different ways of converting energy that is acquired from fuel into mechanical, electrical and hydraulic energy and heat supplied to the technological receivers of energy on ships significantly affect the possible solutions of energy systems and their efficiency. Figure 1 shows a diagram of the most common energy system solutions depending on the way energy is converted. For simplicity's sake the diagram does not distinguish each receiver and has been limited to presenting them together in groups. The "mechanical energy output" indicated in the diagram includes the propeller and other mechanical energy technological receivers, and other receivers are included in the "electricity and heat receivers" groups. Heat can be obtained not only from the fired boiler or nuclear reactor but also from the internal combustion engine or fuel cell as waste heat (dashed line in the diagram). Pneumatic energy has been omitted in order to simplify the diagram. The designation "int. combust. engine" or "steam engine" may represent both a 
piston engine and a turbine engine. Depending on the heat carrier and the value of its exergy and enthalpy, waste heat can be used in the boiler or directly in, for example, air heaters. The diagram shown in Figure 1 can be greatly simplified if the problem is limited to smaller units, for which only diesel oil as fuel is used and there is no significant heat demand. Such units include, for example, small fishing vessels or cutters. In this case it is usually possible to exclude the steam boiler and to replace it with a water boiler because there are no high temperature heating needs. The transfer of mechanical energy from the internal combustion engine to the propeller, i.e. one of the mechanical energy receivers, can take place either directly or through a mechanical transmission, via either electric power (electric transmission) or hydraulic power (hydraulic transmission). In energy system solutions, e.g. on larger fishing vessels, group or central hydraulic systems may be used to power all or part of the fishing and deck equipment. This situation takes place when the hydraulic pump is driven directly from an internal combustion engine (sometimes separate) or from a mechanical transmission. A similar situation may occur when electrical energy is extensively used instead of hydraulic energy (an all-electric ship).

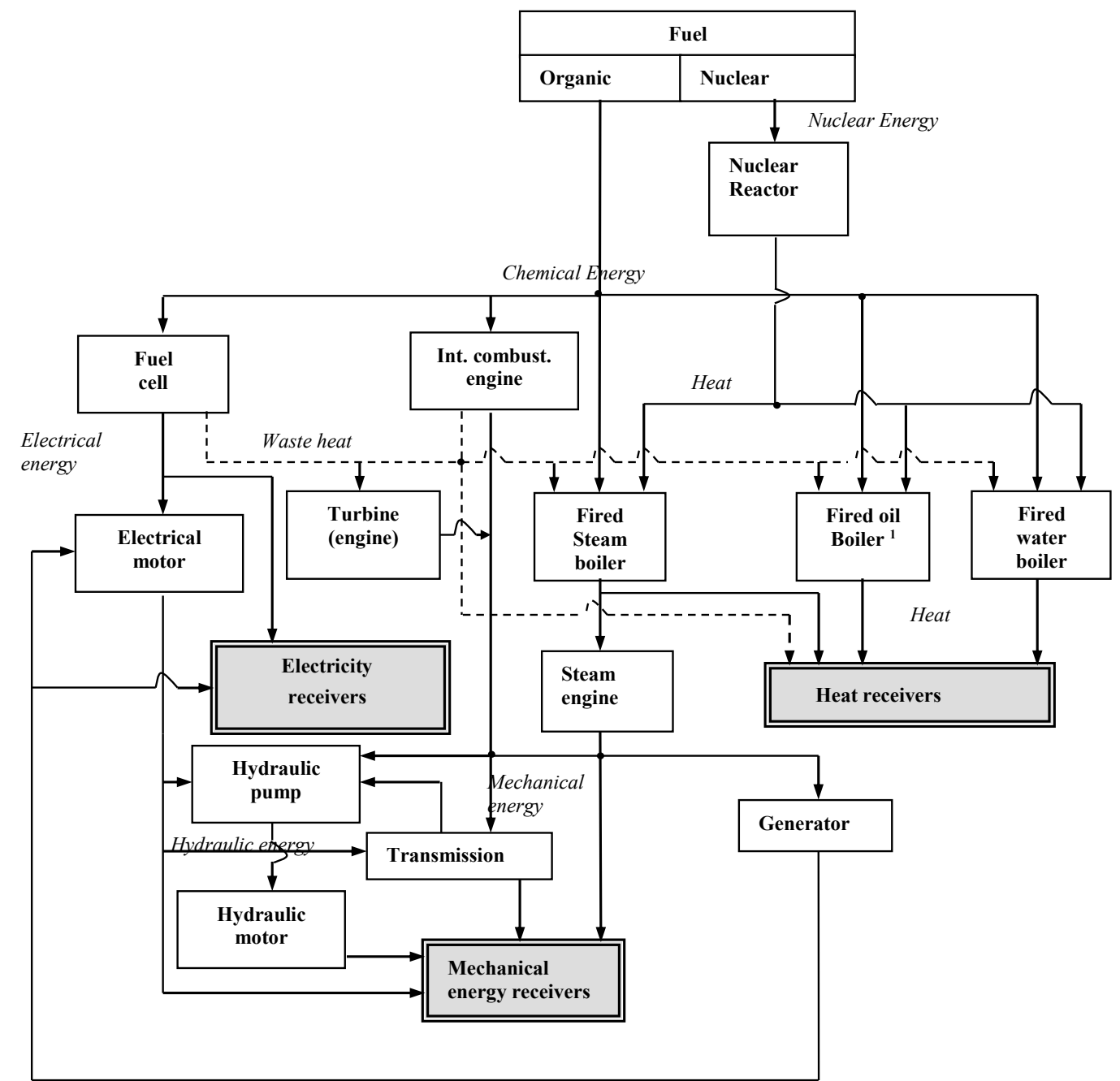

Fig. 1 Possible ways of energy conversion in a ship's energy system the working medium is thermal oil

Source: own study

Ships that are fully electrified may have a power plant with several combustion generating sets which are switched on depending on the electrical power demand required by the main drive and other receivers.

The diagram presented here also covers situations when electrohydraulic drives are used for technological receivers of mechanical energy. The term hydraulic motor also covers a hydraulic cylinder. A number of devices that are receivers of mechanical energy may have various types 
of additional gearboxes that affect the efficiency of the device itself (such gears are not shown in the diagram since they constitute an integral part of the device and are therefore already a usable energy receiver). The most advantageous solution for the energy system in view of its efficiency is the one whereby the chain of energy conversion of the energy contained in the fuel into useful energy in each form is the shortest and the conversions themselves are carried out with the highest efficiency.

\section{BALANCE SHIELD OF THE SHIP'S ENERGY SYSTEM}

The effective use of fuel energy on a ship determines, in addition to the way it is converted, all receivers of all forms of energy to which it has been transformed. Individual streams of energy reach the final link of the energy chain, where it is converted to either heat or work. Determining the balance shield is extremely important for a proper definition of the energy efficiency of a ship's energy system. In a certain sense, the position of the balance shield can be recognized as arbitrary; however, when trying to compare different energy systems with each other for efficiency reasons the positioning of the balance shield must follow the same rule, i.e. it cannot be placed too far from the primary source, which is the chemical energy of fuel, because in that case it could occur differently for various energy systems. The best way to locate it is to determine the place that is always present in each of the solutions of the considered energy systems.

The energy conversion scheme shown in Figure 1 may be useful to determine the balance shield. An exemplary balance shield of the energy system of a small fishing vessel was built on its basis and is shown in Figure 2.

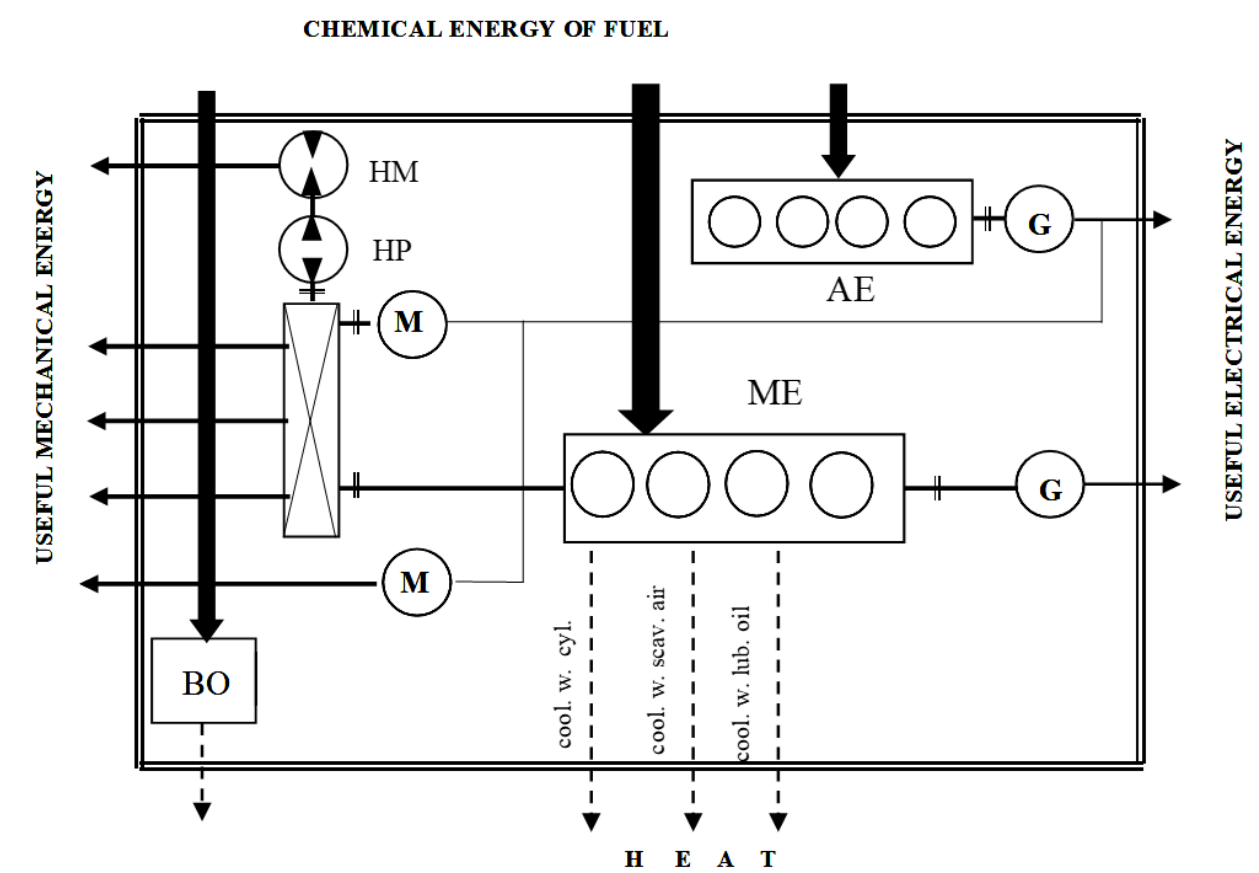

Fig. 2 Exemplary balance shield of the energy system of a small fishing vessel

ME - main engine; AE - auxiliary engine; G - generator; M - electrical motor; BO - fired boiler;

Source: own study based on (Matejski et al., 2013)

Useful energy streams are led out beyond the balance shield of the system, e.g. a stream of mechanical energy for the propulsion drive and other technological devices, a stream of electrical energy supplying the unit-specific technological equipment, transshipment facilities, auxiliary machinery in a power plant, air conditioning and ventilation equipment, lighting, radio and navigation equipment and heat flow for heat receivers. It is justified to leave all of the simpler transformations of less valuable energy into a higher form inside the balance shield.

The most useful energy is electrical energy, then mechanical energy. The least valuable in this approach is heat (Balcerski, 2007). Likewise, all main engine handling devices are left inside the 
power shield if they are driven directly from it, such as cooling water or lubricating oil pumps, as they are not considered to be separate mechanical energy receivers. However, when cooling water pumps are driven by electric motors they are considered to be the receivers of a usable electricity stream. In the former case, pumps driven directly from the engine reduce the amount of useful energy; in the latter case they increase. However, this does not result in significant differences in fuel consumption by engines but in more different streams of useful energy. The possible differences in efficiency are for this reason often negligible and may then be omitted (Balcerski, 2007). However, in order to avoid mistakes, energy systems which are compared should use similar pump drive options, or the balance shield should be guided so that the mechanical energy transmitted from the engine to the driven pumps is treated as useful energy or the pumps should be left inside the shield in case of an electric drive.

\section{EFFICIENCY OF THE ENERGY SYSTEM}

In the past, for older cargo ships with low energy needs besides the propulsion, the efficiency of the power plant was defined as the ratio of the power supplied to the propeller or (useful energy stream) to the chemical energy stream delivered in the combusted fuel. Therefore, due to the small values of other streams of useful energy, i.e. electricity and heat, they were ignored, and the defined efficiency was also called the "general efficiency of the power plant". On technological units, such as a fishing vessel, such a definition of efficiency turns out to be too simplistic.

The term "general efficiency of the power plant" as equivalent to the concept of "drive efficiency", without any additional explanation, can be considered ambiguous and misleading as it is also close to the concept of "propulsion efficiency". This latter efficiency is defined as the ratio of towing power to the power delivered to the propeller (Chachulski, 1988), (Krępa, 1989). Propulsion efficiency is also defined as the ratio of towing power to power on the clutch of the main engine (Dudziak, 1988). On the other hand, the definition of "drive efficiency" states that this is the ratio of the towing power to the energy stream contained in the fuel combusted in the main engines (Krępa, 1989), (Wojnowski, 2002). As can be observed, the term "efficiency" most often has a contractual character, as the terms are differently formulated by the authors and are not covered by standards. The main differences concern the type of useful energy stream (Balcerski, 2007).

A more appropriate evaluation of the power plant of modern ships is the efficiency of the power plant, which is this same as the efficiency of the energy system, and can be represented by the relation:

$$
\eta_{U E}=\frac{P_{N S}+P_{E L}+\dot{Q}_{C}}{\sum_{i} \dot{m}_{p a l_{i}} W_{d_{i}}},
$$

where:

$P_{N S}$ - power delivered to the propeller,

$P_{E L}$ - generator power,

$\dot{Q}_{C}$ - useful heat power,

$\dot{m}_{p_{i} l_{i}}$ - mass stream of $i$-kind fuel,

$W_{d_{i}}$ - lower calorific value of $i$-kind fuel.

As can be observed in Figure 2, in the case of technological units, including fishing vessels, on the side of the useful mechanical energy stream, in addition to power delivered to the propeller, streams of energy delivered to the other technological receivers of mechanical energy should also be included. Determining the total stream of useful mechanical energy by $P_{E M}$, the expression for the energy efficiency of the energy system is obtained:

$$
\eta_{E U E}=\frac{P_{E M}+P_{E L}+\dot{Q}_{C}}{\sum_{i} \dot{m}_{p a l_{i}}{ }^{W} d_{i}} .
$$


In the case of ship power systems, where the number of technological receivers of mechanical energy is limited in comparison to large fishing vessels or other technological units, for calculation purposes it is convenient to divide the stream of useful mechanical energy $P_{E M}$ into individual components $P_{E M i}$. When there is one kind of fuel on the ship, equation (2) will take the form:

$$
\eta_{E U E}=\frac{\sum_{i} P_{E M_{i}}+P_{E L}+\dot{Q}_{C}}{\left(\dot{m}_{p a l_{S G}}+\dot{m}_{p a l_{S P}}+\dot{m}_{p a l_{K O}}\right) W_{d}},
$$

where:

$\dot{m}_{\text {pal }_{S G}}, \dot{m}_{\text {pal }_{S P}}, \dot{m}_{\text {pal }_{K O}}$ - fuel mass streams consumed by main engines, auxiliary engines and the boiler.

This is a general dependence that corresponds to different structures of the energy system. In the absence of a fired boiler or diesel generator set, a zero value for the respective fuel streams should be assumed. In the above equation (2), individual streams of useful energy, depending on the operational state of the ship, are different.

In the case of fishing vessels, for example, there are various energy needs during, for example, free-sailing, trawling or while standing in port; therefore, there is no total useful energy available here, i.e. it is not assumed that the main engine, generator, boiler and all of the receivers are always working simultaneously. On the other hand, the useful energy that is actually used in the given operating state and source that supplies it is taken into account. Equation (3) as well as the previous equations, (1) and (2), are always related to interim values of all energy streams. Determining the value of these streams on units that are already in operation requires simultaneous measurements of the parameters used to determine them in a given state of the energy system. At the design stage, the value of efficiency is determined by theoretical calculations. This makes it possible to compare many variants of solutions. It is assumed that the most energy-consuming operating condition of a unit is usually compared.

Having knowledge of ship operating states is very important from the point of view of energy management. During their operation the energy needs to vary, and the energy system can work with different energy efficiency depending on the range of its use and load of different receivers. It is therefore important to identify these states and to determine efficiency primarily for the most energy-consuming and long-lasting operating states.

\section{METHODOLOGY OF CALCULATING EFFICIENCY ON THE EXAMPLE OF A SELECTED SOLUTION OF THE ENERGY SYSTEM}

A particular solution of the energy system is a system that corresponds to the concept of allelectric ships. The solution of such an energy system for a fishing vessel is shown in Figure 3.

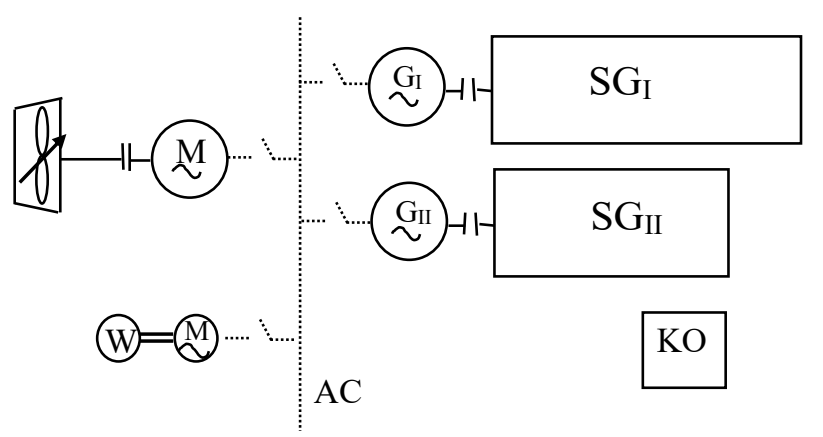

$S G_{\mid}, S G_{\|}-$main engines
$W$ - trawl winch
$K O$ - fired water boiler
$M-$ electric motor
$A C$ - alternating current
$G_{\mid}, G_{\| l}$ - generators

Fig. 3. Energy system for a fishing vessel of the all-electric ship type Source: own study based on (Matejski et al., 2013)

In the system considered here, the hydraulic drive may occur in addition to or instead of the electric drive of the receivers, but this will cause the energy system to lose its effectiveness (less 
efficiency). The essence of the method of calculating the energy efficiency of energy systems is to build a flow chart of energy streams.

Figure 4 shows the flow chart of energy streams for the example of the energy system shown in Figure 3.

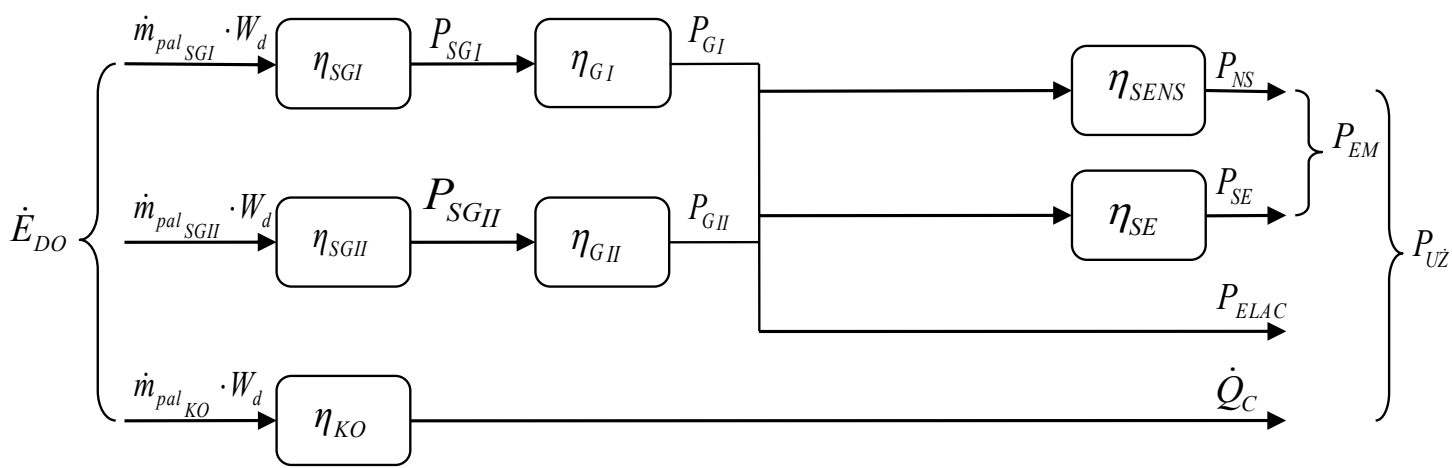

Fig. 4 Flow chart of energy streams for the energy system of a fishing vessel of the all-electric ship type

$\dot{E}_{D O}$ - incoming stream of energy; $P_{E L A C}$ - stream of electric energy (alternating current);

$P_{E M}$ - streams of mechanical energy; $P_{G_{I}}$ - generator power driven by the first engine $P_{G_{I I}}$ - generator power driven by the second engine; $\boldsymbol{P}_{N S}$ - power directed to the propeller;

PSE - electric motor power; $P_{S G_{I}}$ - power of the first engine; $P_{S G_{I I}}$ - power of the second engine;

$P_{U \dot{Z}}$ - streams of useful energy; $\dot{Q}_{C}$ - heat stream produced by fired boiler (boiler power);

$W_{d}$ - fuel of lower calorific value; $\dot{m}_{p a l_{K O}}$ - stream of fuel consumed by the fired boiler;

$\dot{m}_{p a l_{S G I}}$ - stream of fuel consumed by the first engine; $\dot{m}_{p a l_{S G I I}}$ - stream of fuel consumed by the second engine; $\eta_{K O}$ - fired boiler efficiency; $\eta_{S E}$ - electric motor efficiency; $\eta_{S E N S}$ - efficiency of the electric motor driving propeller; $\eta_{S G I}$ - efficiency of the first engine;

$$
\eta_{S G I I} \text { - efficiency of the second engine. }
$$

Source: own study based on (Matejski et al.,2013)

\section{METHOD OF CALCULATION}

\section{Case I}

The values of the fuel streams supplied to the internal combustion engines and to the fired boiler are known and lower calorific values of the fuels are also known.

The values of all mechanical and electrical energy streams at the output of the energy system and the stream of heating water $\dot{m}_{w}$ and its temperature rise $\Delta t_{w}$ are also known, as is the specific heat capacity of water $c_{p_{w}}$.

Input data: $\dot{m}_{p_{\text {all }} S I}, \dot{m}_{\text {pal }_{S G I}}, \dot{m}_{\text {pal }_{K O}}, \dot{m}_{w}, W_{d}, \Delta t_{w}, c_{p_{w}}, P_{N S}, P_{S E}, P_{E L A C}$

Output data: $\eta_{E U E}$.

The heat stream $\dot{Q}_{C}$ contained in hot heating water is determined from equation (4).

$$
\dot{Q}_{C}=\dot{m}_{w} \Delta t_{w} c_{p_{w}} .
$$

The energy efficiency of the energy system is then calculated from the equation:

\section{Case II}

$$
\eta_{E U E}=\frac{P_{N S}+P_{S E}+P_{E L A C}+\dot{Q}_{C}}{\left(\dot{m}_{p a l_{S G_{I}}}+\dot{m}_{p_{\text {al }} l_{S I}}+\dot{m}_{p a l_{K O}}\right) W_{d}} .
$$

The value of power directed to propeller $P_{N S}$ is not known.

The power of the generators driven by engine no. $1 P_{G_{I}}$ and no. II $P_{G_{I I}}$ is known. 
The power of electric motors $P_{S E}$, stream of useful electrical energy $P_{E L A C}$, heating water stream $\dot{m}_{w}$, its temperature increase $\Delta t_{w}$, and the specific heat capacity of water $c_{p_{w}}$ are known. Also known are the values of proper efficiency of energy conversion: $\eta_{S E}$.

Input data: $\dot{m}_{p a l_{S G I}}, \dot{m}_{p a l_{S G I I}}, \dot{m}_{w}, W_{d}, \Delta t_{w}, c_{p_{w}}, P_{G_{I}}, P_{G_{I I}}, P_{S E}, P_{E L A C}, \eta_{S E}, \eta_{G_{I}}, \eta_{G_{I I}}$.

Output data: $\eta_{E U E}$.

The heat stream $\dot{Q}_{C}$ contained in hot heating water is determined from equation (4).

Power directed to the propeller can be calculated from the equation:

$$
P_{N S}=P_{G_{I}}+P_{G_{I I}}-\frac{P_{S E}}{\eta_{S E}}-P_{E L A C} .
$$

The energy efficiency of the energy system of a fishing vessel is then calculated from equation (7).

$$
\eta_{E U E}=\frac{P_{G_{I}}+P_{G_{I I}}+P_{S E}\left(1-\frac{1}{\eta_{S E}}\right)+\dot{Q}_{C}}{\left(\dot{m}_{p a l_{S G_{I}}}+\dot{m}_{p a l_{S G_{I I}}}+\dot{m}_{p a l_{K O}}\right) W_{d}} .
$$

\section{ALGORITHM FOR CALCULATING THE EFFICIENCY OF A SHIP'S ENERGY SYSTEM}

A general block diagram was developed on whose basis a computer program was built for the proposed method of calculating the efficiency of the energy system. For easer use of the program in the user interface it is possible to visualize the technological schemes of the energy systems and the flow patterns of the energy streams.

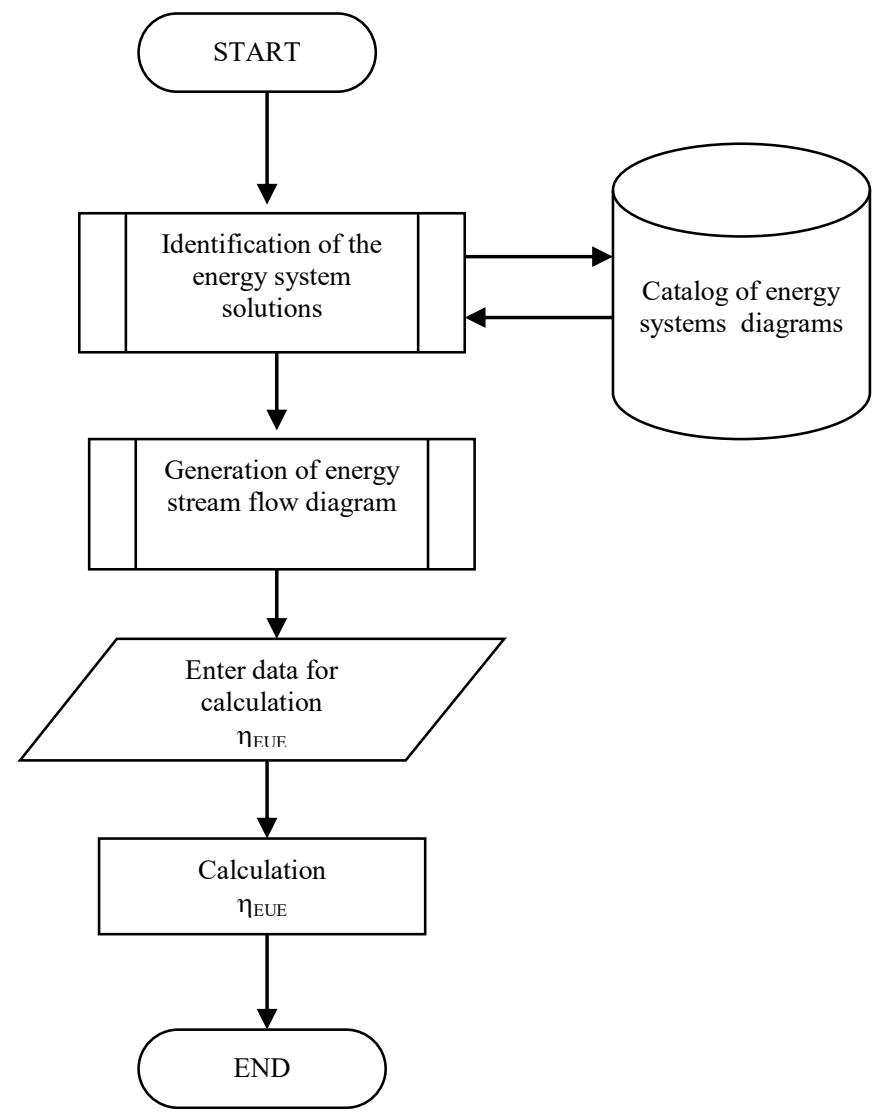

Fig. 5 General block diagram of calculating energy efficiency of a ship's energy system Source: own study 


\section{CONCLUSIONS}

A ship's energy system, due to the complexity, structure and demand for different types of energy, requires a careful approach in the design phase and later in their rational exploitation. Solutions with the shortest and most efficient energy transformation chains should be sought, particularly useful are energy balances in various operating states. A good measure of the quality of the power plant solution and its proper operation is the energy efficiency of the ship's energy system. The article presents the place of the balance shield based on the example of the energy system of a fishing vessel, which is essential in determining its efficiency. The efficiency of the energy system of fishing vessel can be determined in various operating states. A method for determining the efficiency was proposed depending on the available input data set, based on energy stream flow charts. The developed computer program based on a given method can be useful for ship owners as well as for designers of new or upgraded energy systems.

\section{REFERENCES}

Balcerski A. (2007). Modele probabilistyczne w teorii projektowania i eksploatacji spalinowych siłowni okrętowych. Fundacja Promocji Przemysłu Okrętowego i Gospodarki Morskiej. Gdańsk.

Chachulski K. (1988). Podstawy napędu okrętowego. WSM. Gdynia.

Krępa J. (1989), Okrętowe układy energetyczno-napędowe. WSM. Gdynia.

Dudziak J. (1988), Teoria okrętu. Wydawnictwo Morskie. Gdańsk.

Wojnowski W. (2002). Okrętowe siłownie spalinowe. AMW. Gdynia.

Matejski M., Michalski R., Zeńczak W. (2013). Opracowanie metodyki obliczania sprawności układu energetycznego kutrów rybackich. Szczecin. 